Proceedings

\title{
Drawing and Cognition in Learning Graphics and in Graphic Learning ${ }^{\dagger}$
}

\section{Enrico Cicalò}

Dipartimento di Architettura, Design e Urbanistica, Università degli Studi di Sassari, 07100 Sassari, Italy; enrico.cicalo@uniss.it

+ Presented at the International and Interdisciplinary Conference IMMAGINI? Image and Imagination between Representation, Communication, Education and Psychology, Brixen, Italy, 27-28 November 2017.

Published: 25 December 2017

\begin{abstract}
This article discusses the relationships between drawing and cognition starting from the concept of graphic intelligence, and going beyond the classic approach, widely deepened in the literature from the field of clinical neuropsychology, linked to a concept of drawing as tool for the evaluation of the cerebral connections functionalities in cases of particular disabilities. Instead, this article analyses the relationships between drawing and cognition focusing to learning processes. Therefore, drawing is considered not only as a product with which to interpret the psychological, bodily-kinesthetic and cognitive spheres of the individual, but also as a tool for stimulating the development of such spheres.
\end{abstract}

Keywords: drawing; cognition; graphic intelligence; graphicacy; learning

\section{Drawing and Cognition}

Research on the relationship between drawing and cognition have been largely developed in the field of clinical neuropsychology in order to rehabilitate patients affected by particular forms of neurological disabilities. Within these studies, drawing is generally considered as a tool through which to test the functionality of brain connections [1,2]. For this reason, these studies generally focus on drawing as a process aimed to graphically reproduce what has been observed, and therefore through which to test the ability to command gestures in a conscious way. Accordingly, in literature the process of drawing is generally observed and described mainly in relation to the reproduction of what is perceived, with emphasis on the stratification of graphic signs corresponding to the various perceptive phases.

This literature considers Van Sommers's works $[3,4]$ to be the only studies that has really analyzed the relations between drawing and cognition this studies describe two different processes: the first linked to perception and the second linked to graphic production. The first model, linked to the process of perception, is finalized to the re-copying of a subject that is articulated, consistently with the Marr's model [5], in three hierarchically structured passages:

- a first phase in which the perceived image is represented through a synthetic two-dimensional description based on variations in intensity in which background and figure are not distinct;

- $\quad$ a second phase in which the previous representation is enriched by information about surfaces and placed in a three-dimensional reference system centered on the observer through an estimation of distances and orientations;

- a third phase in which, the information relating to the three-dimensionality of the structure of the object represented is completed.

The second model is about the graphic production. It consists of four phases. In the act of copying a perceived or a remembered subject, the draughtsman makes a series of choices or 
decisions (depiction decisions) relating to the characteristics of the drawing. They concern dimensions, orientations, level of detail, etc. Then, the drawing is divided into parts that determine the production strategy. In this regard, two different strategies can be identified: one of hierarchical type, respectful of one form of image organization, and the other independent from it. The identified parts are reproduced according to particular sequences depending on whether the subject is known or not. In the first case the sequence is defined as a routine program (routine planning), and in the second case it is defined as a contingent planning program, that implies a different approach to representation (problem solving). Finally, in performing the representation, there can be a series of constraints, both of economic and of instrumental nature (articulatory and economic constraints).

From a different point of view, the relationships between drawing and cognition can be analyzed in relation to the ability not to represent but to communicate. Indeed, the development of graphic skills is not different from that of the language skills. Through drawing it is possible to graphically communicate concepts using a particular graphic lexicon and particular syntactical rules that need to be acquired through experience and exercise. Without these, the system of graphic expression remains at a basic level exactly as it happens in subjects not exposed to verbal stimuli during their cognitive development [6].

Therefore, drawing is an activity that produces graphic outputs from inputs of different types: visual, perceptive and mnemonic but also linguistic [7]. It must be understood as a system in which the ability to produce the graphic outputs is closely linked to the ability to provide inputs [8]. For this reason, graphic capabilities cannot be considered as separate from others [9]. Indeed, the graphic skills have to be considered as a system closely connected to various other skills as motor, imaginative, interpretative, narrative, mnemonic, perceptive, logical, critical and aesthetic skills. Improvements in one of these have an impact on the general capacity of drawing. Thus, the drawing is configured, to the pair of the writing, as a global skill [10].

\section{Drawing and Cognition in the Multiple Intelligence Theory}

This concept of multiple and different but closely interlinked intellectual abilities is at the basis of the theory of multiple intelligence. In the book Frames of Mind. The theory of Multiple Intelligence, published in 1983, Howard Gardner-professor of Cognitive Science at the Harvard University-defines as intelligence the ability to solve problems or to create products appreciated in a cultural context [11]. According to his theory on multiple intelligences, intellective human competences are various, relatively autonomous and their nature and their articulation are not definable, because they tend to shape themselves and to combine among them in a variety of adaptive ways. Indeed, they form a continuum, rather than being distinct in a rigid and definite manner. Therefore, every type of intelligence, thought as isolated and autonomous, configure themselves as "fictions", or scientific constructs potentially useful to explore scientific issues. Using this explorative strategy, Gardner identifies seven main types of intelligence: the linguistic intelligence, the logical-mathematical intelligence, the musical intelligence, the spatial intelligence, the bodily-kinesthetic, the intrapersonal intelligence, and the interpersonal intelligence.

Starting from the previously described definition of intelligence, Gardner claim that many problems are not solvable through linguistic or logical-mathematical propositions, but-mainly in the fields of images and spatial objects - they need to be considered as problem of visual imagination. This ability is traditionally separated from those logic-mathematical and linguistic and it is often defined "the other intelligence". This is the spatial intelligence, based on non-verbal languages and opposed, but at the same time complementary, to the intelligences based on verbal languages.

The spatial intelligence has been defined by Howard Gardner as the composition of different skills connected among them. They work as a family and are able to support each other. The ability to recognize images of the same object, the ability to visually transform an object in an other or to recognize this transformation, as well as the skill to make a graphic representation of the spatial information belong to this family. Thus, the graphic skills would be part of the spatial intelligence 
and it would be also the basis of the ability to represent in two or three dimensions the real world by using symbolic codes, as in the case of geographic and topographic representations, diagrams, and geometric figures.

Consequently, the research of Gardner introduces an other form of intelligence that is responsible of the graphic expression of spatial concepts: this is the graphic intelligence [12], or the skill to use the graphic abilities, and more in general the coordination of eyes, mind and hands-perception, cognition and representation-in order to solve problems and to make effective results for the generation of new knowledge.

Since the relations between drawing and thought have been already studied [3,14-15], in the literature the concept of graphic intelligence has been prevalently studied only as part of other more complex forms of intelligence, as the spatial one just described, or only focusing on its single parts, as for example, The Thinking Hand by Juhani Pallasmaa [16], the Graphic Thinking by Paul Laseau [17], Thinking with a Pencil by Henning Nelms [18], and The Mind's Eye by Eugene S. Ferguson [19] that deepen the three components of the integration among eye, mind, and hands.

\section{Multiple Intelligence and Graphic Intelligence}

In general, intelligence is defined as the ability to solve problems, or to create products that are appreciated within one or more cultural contexts [11]. It has been widely discussed and demonstrated that there are many human intellectual skills relatively autonomous that in the theory of multiple intelligences are called "human intelligences", the number of which is neither irrefutably fixed nor universally recognized. In fact, rather than being rigidly distinct and defined, the different kinds of intelligence form a continuum. Therefore, these intelligences are "fictions", namely scientific constructs potentially useful to illuminate scientific problems. Every human intellectual skill involves a set of problem-solving abilities that allow the individual to solve problems or difficulties in which he is undefeated and, if so, to create an effective product. Also, it involves the ability to find or create problems, in this way preparing the ground to the acquisition of new knowledge. Applying this definition to the graphic skills, it emerges that they can and should actually be considered an autonomous form of intelligence. So far, in the literature, such skills have been instead assimilated to other broader intellectual human abilities such as the spatial intelligence [19] and the visual intelligence [11]. Actually, they also are considered an amalgam of skills [12], to the point that in this area of research the word visual often comes to be used as a synonym of spatial, because spatial humans intelligence is closely related to the observation of the environment. Therefore, in this continuum of human intelligences, we can identify, confine and define the graphic intelligence [11], which is certainly in close relation with other forms of intelligence and particularly with the spatial and the visual one.

The spatial intelligence is based on the ability of individuals to perceive the world and to operate on the basis of such perceptions. According to Gardner, it includes skills very different from each other, as the ability to perceive visually, to represent graphically, and to create mental images through imagination. These are capacities related but distinct from each other and thus deserving of being analyzed independently. Howard Gardner writes that it is possible that these operations are independent from each other and that they can be developed or damaged separately. Nevertheless, like rhythm and melody cooperate with each other in music, the previously mentioned capacities typically occur together within the space. Actually, they operate as a family, and each skill may well enhance by the other. These spatial skills are used in various different fields. They are important for the orientation in different situations, from enclosed areas to oceans; relies on them the recognition of objects and scenes, both when they are in their original context and when it has changed. This form of intelligence is also used when working on graphical representations-two-dimensional or three-dimensional versions of scenes from the real world-as well as in connection with other symbols, such as in geographical or topographical maps, diagrams or geometric figures [20].

However, in discussing the spatial development of intelligence in different evolutionary stages, since the Piaget studies [21], Gardner recognizes how the different components of the amalgam of skills that he defines as spatial intelligence are developed independently. Indeed, children develop 
rapidly spatial understanding, but the representation of this knowledge involves an additional and different range of difficulties. The expression of this understanding through a symbolic code is more difficult. Therefore, another kind of intelligence seems to distinguish itself from the spatial one and to become useful and necessary to codify the understanding: the graphic intelligence, precisely.

The graphic intelligence can be defined as the ability to address and resolve problems through the coordination of eye, mind and hand-namely perception, thinking and representation-in the way in which we have seen Galileo observing, understanding and representing - not necessarily in this order-the lunar surface; developing that scientific imagination that Bruno Latour calls "thinking with the eyes and hands [22], that is at the basis of the visualization process and of the making visible through graphic representation.

Thinking with eyes and hands, dealing with problematic situations proceeding through graphic experimentations [23], is not only constitutive of design disciplines, but actually underlies the development of thought in a much broader disciplines and domains embracing the entire science and, as we shall see, beyond.

Ian Macfarlane Smith claims that, after that a person has achieved an adequate verbal expertise, his progress in science [11] is determined by his spatial ability. As Gardner writes, very developed spatial intelligence is an invaluable resource. In some activities this skill is essential: as the case of sculptors or mathematical topologists; but there are many other fields in which the only spatial intelligence might not be enough to produce competence [24]. Moreover, the graphic intelligence differ both from that spatial discussed by Gardner and from the visual one discussed by Robertson [25] and even before by Rudolf Arnheim [25], according to whom the visual images are not only a useful aid to the thought, but even their primary source. The most important operations of thought rely directly on our perception of the world. On sight are based and are constituted our cognitive processes. A truly productive thinking in any area of cognition, Arnheim writes, takes place within the visual imagination. Enhancing the role of vision, he minimizes that of language. Only explicating by image processes or concepts, he argues, it is possible to think clearly about them. Consequently, the visual and spatial intelligence contribute significantly to scientific and artistic thinking [26]. Of the same opinion was Albert Einstein that, thinking in pictures, came to hypothesize his fundamental discoveries that, as he recognizes, are derived more from spatial thought that from a purely mathematical reasoning. As he explained, the words of the language, both written and spoken, do not seem to have any role in his mechanism of thought. The psychological entities that seem to serve as elements in thought are certain signs and images more or less clear which can be voluntarily reproduced or combined. The factors mentioned above are, in his case, of visual and of muscular type [27]. However, the ability to produce mental images may not be sufficient. There are situations in which reasoning by images allows to solve a problem or achieve a cognitive result otherwise unachievable. At this point comes into play the drawing, the most suitable tool for the transmission of this type of knowledge [27] and, therefore, that graphic intelligence able to translate mental images through drawn images.

\section{Learning Graphics: Developing Graphic Intelligence}

The exploration and the definition of the concept of graphic intelligence force us to focusing attention on drawing as cognitive process and as tool for thinking, so recalling the need to strengthen graphic education within the educational paths. In this way, the graphic education, the drawing teaching, the graphicacy regain their centrality and claim equal dignity as literacy, numeracy and oracy on which school tends to invest more.

Human beings seem to have an innate ability to graphically represent concepts and images, but the achievement of full competence requires that students have to be exposed to a rich graphic environment and has the motivation to acquire fluidity [28]. Peripheral skills often come much later in individual development, and can be learned outside of any critical period. In opposition, since drawing requires a limited period of time to be fully activated, this would suggest that it is essential to human cognition like other fundamental functions such as verbal or manual language systems. For these reason, drawing has to be considered a central rather than peripheral cognitive ability. 
Therefore, any complete understanding of the mind must incorporate this ability without treating it as an accessory or peripheral system linked only to aesthetic or expressionist intentions. Drawing rather serves as another way to convey concepts, and its study is embedded into the understanding of human communication, human cognition and human nature [29].

The adequacy of the vocabulary of a language to discuss a particular topic can be significant of the importance of that topic in the culture to which the language belongs. In Italy, the concept of literacy is generally used, speaking of initiation of pre-school pupils to the communication languages, only in reference to the education of verbal languages, both in writing and in reading. Although in the other cultures the setting of the children training courses is in any case problematic, it is important to observe the richness of the vocabulary available to discuss these topics. The English language, for example, offers the possibility of differentiate literacy in at least four variants: literacy, oracy, numeracy and graphicacy, respectively referring to the education of the written and the spoken word languages, of the numbers, and finally of the graphic signs. They are often defined as "the four axes" [30] in the learning game; but when it comes time to discard one of them, the one you choose is always that of graphicacy, or the ability to communicate through visual messages such as images, maps, diagrams, graphics, symbols and drawings.

Analyzing the educative paths, it is possible to highlight how the verbal languages are more valorized than those non-verbal. Furthermore, in the field of those non-verbal, the perceptive aspects are preferred to those productive leading, in this way, to the weakening of the graphic intelligence. The education of the vision and of the perceptive skills is often considered as similar or alternative to the education of the graphic skills. Consequently, the first tends, for various reasons, to replace the second undermining the possibility to develop one of the most important cognitive tool, that is precisely the graphic thinking. However, learning the languages based on signs, both verbal and non-verbal, concerns not only the decoding processes of the signs perceived but also the complex process of coding of the same signs [31]. So, also the learning of images-based languages requires the development of the coding and decoding the visual information. Therefore, it makes sense to speak of graphic communications to refer to the coding of the message that will be then decoded through the perceptive processes usually associated with the expression of visual communication.

The higher education of teachers is mainly focused on the visual education rather than on the graphic education, with consequence on the methods they will use in the school classes during their entire career and on the education of generations of pupils and students. These teachers will not have adequate tools for stimulate not only the visual intelligence but also the graphic intelligence too [32], thereby renouncing the use of these skills to develop and enhance learning. This is also the effect of the lack of adequate teaching and research spaces within the training courses for teachers who will be called to foster the development of these skills in tomorrow's schoolrooms [33].

Learning graphics and developing the graphic intelligence it is important not only into the education curricula of specific careers, but also in the broader general education, reaffirming the role of graphic representation as communication language for the translation of imagination in images, and for the development of thought in the most different scientific and professional fields and in all the steps of the educative paths. Furthermore, it has been underlined the need to emphasize the autonomy of the graphic intelligence and at the same time the usefulness to strengthen its relations with others kinds of intelligence, so that it will be possible to recuperate the cognitive potential that has been lost, for the restriction of graphic skills to particular professional categories and to few education careers. Therefore, graphic languages have to move from the specialist conception in which they are today confined, towards a broader conception in which they work as tools for the expression, the communication, and the thought, not only in the fields of arts, of design and of technic, but also-among others - in those scientific and literary.

\section{Graphic Learning: Using Graphic Intelligence}

Over time, numerous prejudices have been stratified on the word drawing, which have greatly weakened its meaning and potential. Drawing is traditionally and generally considered an activity linked to a particular individual talent or specific professions. Its real potential as an instrument of 
knowledge, learning and thought is often ignored. Instead, as the neurosciences explain, drawing allows us to activate different ways of thinking and seeing. When you draw something, you look at it in a different way, focusing your attention on lines, shapes, relationships and details that generally elude to the eye. In our inattentive observation of reality, the brain is satisfied with recognizing what it sees, without deepening the observation, interpretation and understanding of what the eye perceives. Drawing changes the way you look, making active the act of seeing. Indeed, it is a fundamental way of seeing. Milton Glaser explains that when you draw an object, the mind intensely and profoundly concentrates and it is this high level of attention that allows you to grasp things and become fully aware of them [34,35].

In addition to empowering the ability to understand perceived reality, graphic intelligence improves other learning processes. Based on the learning by doing approach [36] and the traditional use of images as a learning strengthening [37,38], experiments have demonstrated how drawing can also be an effective memorizing and learning strategy. It has been shown that the drawing of the information to be stored allows achieving better results than other storage techniques because of its ability to enhance the verbal language with the non-verbal language of the images. Words drawn are better memorized than written words, giving rise to what is called the drawing effect, which fosters the elaboration of mental images associated with the represented object. The effectiveness of this strategy does not depend on the aesthetic quality of the graphic product; even very fast drawings, realized in a few seconds, allow the achievement of the objective. What counts is not the product but the cognitive process that the realization of that product has succeeded in triggering.

This memorization technique goes beyond the simple association of the image with texts typical of didactic illustration that solicits only visual and perceptive intelligence. By fostering the creation of mental images that can then be translated into graphic representation, drawing stimulates graphic intelligence activating the entire family of spatial intelligence, and adding it to the linguistic one traditionally used. Thus, the developed multi-channel cognitive process is clearly more powerful and intense, and it is precisely this intensity of the cognitive strain that allows a stronger rooting of the graphically reworked concepts. Moreover, since drawing implies the control of gesture and movement aimed at the production of representation, the drawing effect would also stimulate kinesthetic intelligence, further enhancing the cognitive process.

\section{Conclusions}

The most recent research in the field of cognitive sciences suggests the existence of important relationships between graphic representation and cognitive development that support the idea of a graphic intelligence independent from the other forms of intelligence that have been until now considered able to describe and contain this particular type of human intellectual competence. Graphical intelligence is the ability to use graphic skills and, more generally, the ability to integrate the use of eye, mind and hand to solve problems of various kinds and generate effective products aimed at creating, acquiring and communicating knowledge.

Therefore, the graphic intelligence should be considered equally important like the best-known linguistic and logical-mathematical intelligence on which the school today tends to focus more. It can complete and enrich the already investigated visual and spatial intelligence that, according to the literature produced so far on the subject, include and coordinate with the skills in the graphic field. Thinking about graphic skills as a form of intelligence obliges us to focus not only on the graphic product but also on the cognitive process that led to the representation of that product. This change of perspective, based on the cognitive potential of drawing, is able to suggest new approaches to didactics at all levels and in all fields of education. Consequently, learning graphics has to be considered preliminary to the graphic learning.

In the different phases of the cognitive development, the relations between drawing and cognition assume different forms. During childhood it is useful to learn graphic skills in order to enhance the different forms of intelligence that are closely interlinked. Furthermore, in the following school path graphic skills are useful to enhance the learning of different disciplines. Thus, the 
transversality of graphic skills emerges, less and less tied to the traditional concept of drawing as a figurative representation of reality and increasingly closer to the idea of drawing as an instrument of thought.

Conflicts of Interest: The authors declare no conflict of interest.

\section{References}

1. Guérin, F.; Ska, B.; Belleville, S. Cognitive processing of drawing abilities. Brain Cogn. 1999, 40, 464-478.

2. Smith, A.D. On the use of drawing tasks in neuropsychological assessment. Neuropsychology 2009, 23, 231.

3. Van Sommers, P. Drawing and Cognition: Descriptive and Experimental Studies of Graphic Production Processes; Cambridge University Press: New York, NY, USA, 1984.

4. Sommers, P.V. A system for drawing and drawing-related neuropsychology. Cogn. Neuropsychol. 1989, 6, $117-164$.

5. Marr, D. Vision; Freeman: New York, NY, USA, 1982.

6. Cohn, N. Explaining 'I can't draw': Parallels between the structure and development of language and drawing. Hum. Dev. 2012, 55, 167-192.

7. Nelson, K. Language in Cognitive Development; Cambridge University Press: Cambridge, UK, 1996.

8. Toomela, A. Drawing as a verbally mediated activity: A study of relationships between verbal, motor, and visuospatial skills and drawing in children. Int. J. Behav. Dev. 2002, 26, 234-247.

9. Gardner, H. Frames of Mind: The Theory of Multiple Intelligence; Basic Books: New York, NY, USA, 1983.

10. Hall, E. Mixed messages: The role and value of drawing in early education. Int. J. Early Years Educ. 2009, 17, 179-190.

11. Gardner, H. Frames of Mind: The Theory of Multiple Intelligence. Available online: https://www.amazon.com/Frames-Mind-Theory-Multiple-Intelligences/dp/0465024335 (accessed on 15 November 2017).

12. Cicalò, E. Intelligenza Grafica; Aracne: Roma, Italy, 2016.

13. Verstijnen, I.M.; van Leeuwen, C.; Goldschmidt, G.; Hamel, R.; Hennessey, J.M. Sketching and creative discovery. Des. Stud. 1998, 19, 519-546.

14. Goldschmidt, G. The Dialectics of Sketching. Creat. Res. J. 1991, 4 123-143.

15. Treib, M. Drawing/Thinking: Confronting in an Electronic Age; Routledge: London, UK; New York, NY, USA, 2008.

16. Pallasmaa, J. The Thinking Hand: Existential and Embodied Wisdom in Architecture; Wiley: Chichester, UK, 2009.

17. Laseau, P. Graphic Thinking for Architects and Designers; Van Nostrand Reinhold: New York, NY, USA, 1980.

18. Nelms, H. Thinking with a Pencil; Bernes \& Noble: London, UK, 1964.

19. Ferguson, E.S. The Mind's Eye: Nonverbal Thought in Technology. Science 1978, 57, 42-46.

20. Piaget, J.; Inhelder, B. La Représentation de L'espace chez L'enfant; Presses Universitaires de France: Paris, France, 1948.

21. Latour, B. Drawing things together. In Representation in Scientific Practice; Lynchm, M., Woolgar, S., Eds.; MIT Press: Cambridge, MA, USA, 1990.

22. Schon, D. The Reflexive Practitioner; Basic Books: New York, NY, USA, 1983.

23. Smith, I.M. Spatial Ability: Its Educational and Social Significance; University of London Press: London, UK, 1964.

24. Robertson, I. The Mind's Eye; Random House: London, UK, 2003.

25. Arnheim, R. Il Pensiero Visivo. La Percezione Visiva Come Attività Conoscitiva; Einaudi: Torino, Italy, 1974.

26. Massironi, M. Vedere Con Il Disegno; Franco Muzzio: Padova, Italy, 1989.

27. Cohn, N. Explaining 'I can't draw': Parallels between the structure and development of language and drawing. Hum. Dev. 2012, 55, 167-192.

28. Balchin, W.G.V.; Colemanm, A.M. Graphicacy Should Be the Fourth Ace in the Pack. Cartogr. Int. J. Geogr. Inf. Geovis. 1966, doi:10.3138/C7Q0-MM01-6161-7315.

29. Cicalò, E. Percezione visiva-Rappresentazione grafica. A/R. Sci. Ric. 2016, 23, 74-79.

30. Cicalò, E. Educazione visiva. Educazione grafica. In Lineis Describere. Sette seminari tra rappresentazione e formazione; Luigini, A., Ed.; Libria: Melfi, Italy, 2017. 
31. Luigini, A. Repraesentāmus. Note sulla didattica tra passato, presente e futuro. In Territori e Frontiere Della Rappresentazione: Territories and Frontiers of Representation; Di Luggo, A., Giordano, P., Florio, R., Papa, L.M., Rossi, A., Zerlenga, O., Barba, S., Campi, M., Cirafici, A., Eds.; Gangemi: Roma, Italy, 2017; Volume 6, pp. 1-1798.

32. Glaser, M. Drawing Is Thinking; Overlook Press: New York, NY, USA, 2008.

33. MacLeod, C.M.; Gopie, N.; Hourihan, K.L.; Neary, K.R.; Ozbuko, J.D. The Production Effect: Delineation of a Phenomenon. J. Exp. Psychol. Learn. Mem. Cogn. 2010, 36, 671-685.

34. Paivio, A.; Rogers, T.B.; Smythe, P.C. Why Are Pictures Easier to Recall Than Words? Psychon. Sci. 1968, 11, 137-138.

35. Lesgold, A.M.; De Good, H.; Levin, J.R. Pictures and Young Children's Prose Learning: A Supplementary Report. J. Read. Behav. 1977, 9, 353-360.

36. Wammes, J.D.; Meade, M.E.; Fernandes, M.A. The Drawing Effect: Evidence for Reliable and Robust Memory Benefits in Free Recall. Q. J. Exp. Psychol. 2016, 69, 1752-1776.

37. Van Meter, P.; Garner, J. The Promise and Practice of Learner-Generated Drawing: Literature Review and Synthesis. Educ. Psychol. Rev. 2005, 17, 285-325.

38. Schwamborn, A.; Mayer, R.E.; Thillmann, H.; Leopold, C.; Leutner, D. Drawing as a Generative Activity and Drawing as a Prognostic Activity. J. Educ. Psychol. 2010, 102, 872-879.

(C) 2017 by the authors. Licensee MDPI, Basel, Switzerland. This article is an open access article distributed under the terms and conditions of the Creative Commons Attribution (CC BY) license (http://creativecommons.org/licenses/by/4.0/). 